\title{
Tendências Espaço-Temporais das Precipitações na Bacia do Rio Ivaí (PR) e a Relação com Alagamentos, Enxurradas e Inundações
}

\author{
Spatiotemporal Trends of Precipitation in the Ivaí River Basin (PR) and the Relation \\ with Floods, Runoff and Inundation
}

\begin{abstract}
Tendencias Espacio-Temporativas de las Precipitaciones en la Cuenca del Río Ivaí $(P R)$ y la Relación con Inundaciones, Aluviones y Dilúvios
\end{abstract}

\author{
Denis Anderson Vieira de Moura ${ }^{1}$ \\ Nathan Felipe da Silva Caldana ${ }^{2}$ \\ Deise Fabiana Ely ${ }^{3}$
}

\begin{abstract}
RESUMO: Os eventos extremos de precipitação causam severos danos no espaço urbano e rural. A bacia hidrográfica do Ivaí abrange uma grande amplitude latitudinal, longitudinal e topográfica, tornando seus estudos complexos e necessários, além de se uma importante área de produção agrícola. Objetivou-se neste trabalho analisar a variabilidade sazonal e a tendência pluviométrica e os seus impactos por meio de ocorrências de alagamento, enxurradas e inundações na mesma. Para a análise da tendência utilizou-se os testes de Correlação Linear $\left(R^{2}\right)$, Mann-Kendall Significance (MK $\mathrm{Z}$ ) e a Monotonic Trend (MC Tau) para as quatro estações do ano. Identificou-se que o verão e o outono são as estações que tiveram as tendências pluviométricas negativas mais acentuadas, principalmente nas regiões sul e leste da bacia. Enquanto as ocorrências de desastres naturais vinculados à precipitação são alarmantes na região, ao todo 127 decretos de situações de emergência foram registrados.
\end{abstract}

PALAVRAS-CHAVE: Vulnerabilidade. Risco climático. Eventos extremos.

ABSTRACT: Extreme precipitation events cause severe damage in both urban and rural areas. The Ivaí river basin covers large differences in latitude, longitude and altitude, making its studies complex and necessary, besides being an important area of agricultural production The the aim of this work was to analyze the variability and tendency of the rainfall and its impacts through occurrences of floods, runoff and inundation episodes in the Ivaí river basin. To analyze trends, Linear Correlation $\left(R^{2}\right)$, Mann-Kendall Significance (MK Z) and Monotonic Trend (MK Tau) tests were used for the four seasons. As a result, it has been identified that summer and autumn are the seasons that had the most pronounced negative trends in rainfall, mainly in the southern and eastern portions of the basin.

\footnotetext{
${ }^{1}$ Universidade Estadual de Londrina. Rodovia Celso Garcia Cid | PR 445 Km 380 | Campus Universitário Cx. Postal 10.011 | CEP 86.057-970 | Londrina - PR. denis.avieiram@gmail.com.

2 Instituto Agronômico Do Paraná. Rod. Celso Garcia Cid, 375 - Conj. Ernani Moura Lima II, Londrina - PR, 86047-902. nathancaldana@gmail.com.

${ }^{3}$ Universidade Estadual de Londrina. Rodovia Celso Garcia Cid | PR 445 Km 380 | Campus Universitário Cx. Postal 10.011 | CEP 86.057-970 | Londrina - PR. deise.ely@gmail.com.
} 
In addition, the occurrences of natural disasters caused by precipitation are alarming in the region, once 127 decrees of emergency.

KEYWORDS: Vulnerability. Climatic risk. Extreme events.

RESUMÉN: Los eventos extremos de precipitación causan severos daños en el espacio urbano y rural. La cuenca del río Ivaí cubre una amplia gama latitudinal, longitudinal y topográfica, lo que hace que sus estudios sean complejos y necesarios, así como un área importante de producción agrícola. El objetivo de este trabajo fue analizar la variabilidad estacional y la tendencia de la lluvia y sus impactos a través de la ocurrencia de de inundaciones, aluviones y diluvios en cuenca hidrográfica del río Ivaí. Para el análisis de la tendencia se utilizaron las pruebas de Correlación Lineal $\left(R^{2}\right)$ MannKendall Significance (MK Z) y Monotonic Trend (MK Tau) para las cuatro estaciones del año. Se identificó que el verano y el otoño son las estaciones con las tendencias de lluvia negativas más pronunciadas, principalmente en las regiones sur y este de la cuenca. Si bien los desastres naturales relacionados con las precipitaciones son alarmantes en la región, se registraron 127 decretos de situaciones de emergencia.

PALABRAS-CLAVE: Vulnerabilidad. Riesgo climático. Eventos extremos.

\section{INTRODUÇÃO}

A atmosfera é um sistema dinâmico que produz diferentes climas em sua associação com as características dos lugares em diferentes escalas têmporo-espaciais. Tais escalas são definidas por meio das interações que ocorrem na própria atmosfera, que podem ser resultantes de mudanças e variações sobre determinado lugar (AYOADE, 1986). Por exemplo, as flutuações variam a curto, médio e em longo prazo e incorporam os eventos extremos. O The Fifth Assessment Report - AR5 salienta que a ocorrência de eventos extremos tende a se tornar mais frequente durante todo o século XXI (IPCC, 2013; SANCHES; VERDUM; FISCH, 2014). Dessa forma, o clima e a periodicidade de seus eventos meteorológicos extremos despertam cada vez mais interesse na sociedade, pois seu conhecimento contribui para o planejamento, na definição de diretrizes que regulamentam o uso e a ocupação do solo, na construção civil e exploração agropecuária (CONTI, 2005; KARIMI; KARIMI; KESHAVARZ, 2017; KARIMI; KESHAVARZ, 2018; LEE et al., 2018; LUNGARSKA; CHAKIR, 2018; PAILLER; TSANEVA, 2018; PATHMESWARAN et al., 2018; ROCHA; SANT'ANNA NETO, 2010; SANCHES; VERDUM; FISCH, 2014; SOMBOONSUKE et al., 2018).

A agricultura, principalmente a produção de grãos, e a pecuária extensiva compõem a base da atividade econômica da região Sul do Brasil e estudos sobre a variabilidade climática se fazem necessário, uma vez que interfere diretamente no tipo de cultura a ser produzida em determinada região, na época de plantio, no uso de agroquímicos e no tipo de irrigação a ser utilizada; além de ter papel decisivo na variabilidade da produção. Trabalhos 
que identifiquem e busquem entender a ocorrência de períodos de seca, chuva intensa, vendavais e geadas contribuem para um melhor planejamento, manejo de culturas e tomada de decisões visando a obtenção de melhores resultados e menores impactos ambientais. A bacia do Rio Ivaí (PR) tem grande parte da sua área destinada às referidas atividades econômicas, demandando por trabalhos que abordem a variabilidade climática e a ocorrência de eventos extremos (AGOVINO et al. 2019; BERLATO; FONTANA, 2003; CALDANA et al., 2019; CALDANA; MARTELÓCIO, 2019; KARIMI; KARAMI; KESHAVARZ, 2018; LUNGARSKA; CHAKIR, 2018; PATHMESWARAN et al., 2018; WIRÉHN, 2018).

Desastres naturais, como consequência de episódios extremos de precipitação, são definidos como fenômenos da natureza que moldam e transformam a paisagem e o espaço geográfico. Caso estes se espacializam em áreas densamente ocupadas podem gerar situações de potencial perigo, ocasionando óbitos, danos de ordem econômica e prejuízos de difícil reparo. As inundações, enxurradas e alagamentos são os mais comuns dentre os eventos hidroclimatológicos. "A inundação é a principal causa de eventos extremos do clima, com $59 \%$ dos registros" (MARCELINO, 2007, p. 16). Tais eventos ocorrem em mais de $80 \%$ das cidades brasileiras e estão associados às severas instabilidades atmosféricas (HUANG et al., 2018; MARCELINO, 2007).

Os alagamentos estão associados a processos de acúmulo de água em determinados locais, principalmente em baixadas, por ineficiência no sistema de drenagem. Já as inundações associadas à precipitação são causadas, principalmente, por uma deficiência na drenagem e pelo volume pluviométrico que atinge a superfície, que ultrapassa a capacidade de escoamento do canal fluvial e gera o transbordamento de um curso hídrico sobre sua área de várzea (muitas vezes ocupadas por construções humanas), enquanto as enxurradas ocorrem num processo similar à inundação, porém com maior área de abrangência e alto poder de transporte. Suas incidências em espaços ocupados e habitados pelo homem causam sérios danos, muitas vezes irreparáveis (MARCELINO, 2007). Esses eventos podem ser intensificados com os cenários de mudanças climáticas e serem ainda mais danosos em conjunto com as constantes mudanças no uso e ocupação do solo sem um adequado planejamento (CHEN et al., 2018; HAMMOND et al., 2015; JAMALI et al., 2018; TANAKA et al., 2017).

Diante do exposto, o presente artigo procura analisar a variabilidade, a tendência pluviométrica sazonal e seus impactos por meio do estudo das ocorrências de alagamentos, enxurradas e inundações na bacia do Rio Ivaí (PR), considerando o recorte temporal de 39 anos (1976 a 2015). 


\section{MATERIAIS E MÉTODOS}

Para o cálculo das tendências sazonais das precipitações foram utilizadas as técnicas da Correlação Linear e seu coeficiente de determinação (R2), significância de Mann-Kendall (MK z) e a tendência monotônica de Mann-Kendall (MK Tau). Essa estatística foi aplicada para o conjunto de dados de 31 estações meteorológicas e postos pluviométricos das redes do Instituto Agronômico do Paraná (IAPAR), Instituto Nacional de Meteorologia (INMET), Agência Nacional das Águas (ANA) e Instituto Águas Paraná. As estações selecionadas para a análise estão distribuídas dentro da área da bacia ou em suas proximidades, propiciando desta forma o processo de interpolação (Figura 1).

Figura 1 - Localização das estações e postos pluviométricos e altitudes na Bacia do Rio Ivaí (PR).

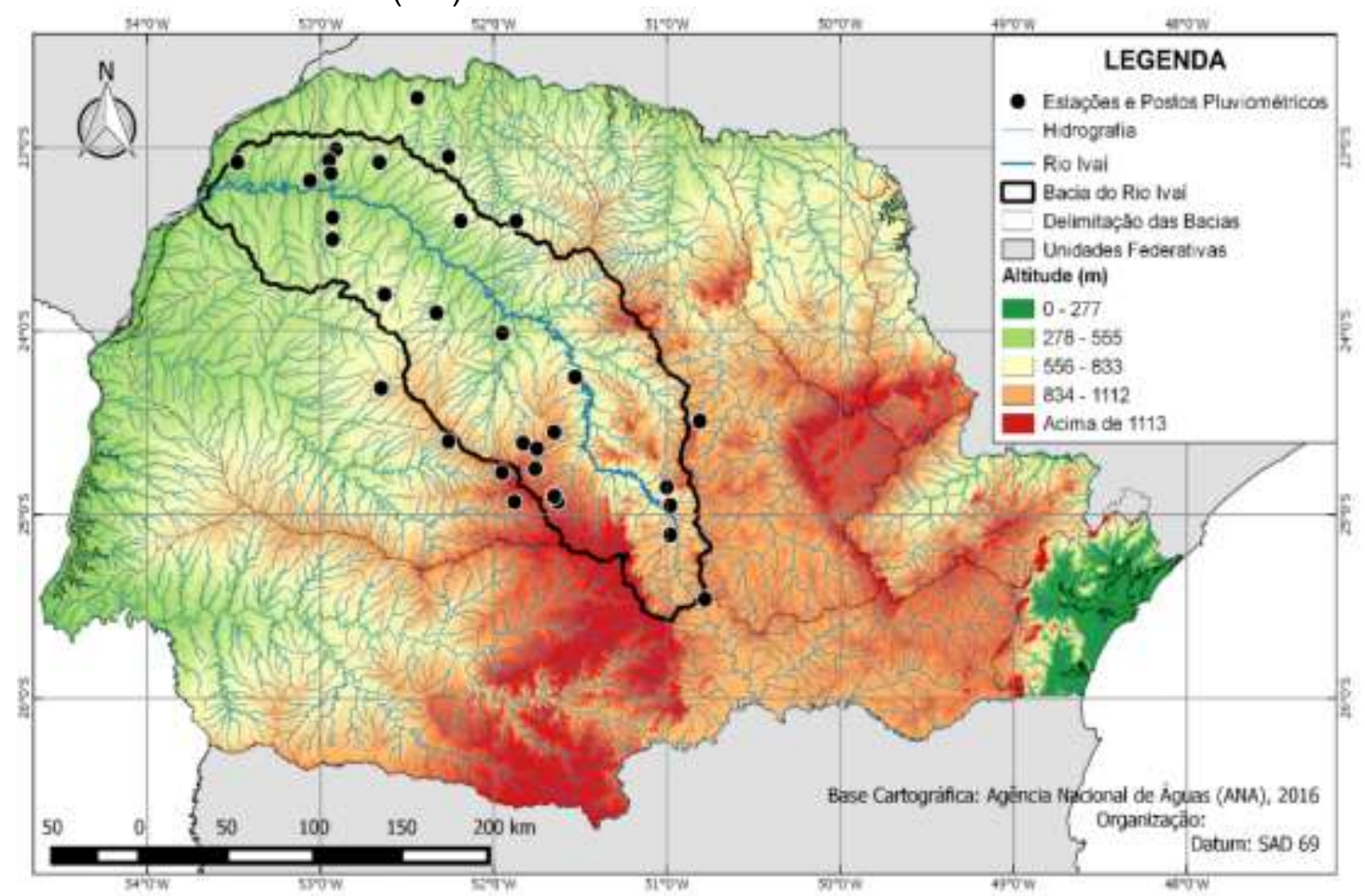

Fonte: IBGE (2018).

A bacia do Rio Ivaí está inserida quase que totalmente no Terceiro Planalto Paranaense, apenas uma pequena porção encontra-se no Segundo Planalto, onde se localiza a nascente do rio que lhe dá nome.

A bacia possui uma área total de 35.845 quilômetros quadrados, ocupando aproximadamente $19 \%$ do território paranaense, sendo a segunda maior em área e o segundo maior rio em extensão do estado. Encontra-se situada entre as coordenadas $22^{\circ}$ $54^{\prime}$ a $25^{\circ} 33^{\prime}$ de latitude sul e $50^{\circ} 44^{\prime}$ a $52^{\circ} 42^{\prime}$ de longitude oeste. Na área da bacia localizase um total de 105 municípios que, juntos, somam $21 \%$ da população do estado do Paraná. 
As principais cidades são: Maringá, Guarapuava, Apucarana, Umuarama, Campo Mourão e Paranavaí (PARANÁ, 2013).

A espacialização dos dados pluviométricos da bacia foi representada por meio da interpolação, utilizando o algoritmo espacial Inverse distance weighted (IDW) no ambiente dos softwares Qgis e Idrisi. A interpolação representa uma operação cartográfica que é executada por meio dos valores registrados em cada posto ou estação. Posteriormente, são calculadas as médias entre os valores de cada ponto fornecido (estações), de modo que os dados obtidos venham suprir as lacunas faltantes (ELY; DUBREUIL, 2017). A utilização desse método tem como principal vantagem, a representação espacial de dados (MUELER et al., 2004).

Os dados que constituíram a base para a interpolação foram tabulados e transformados da escala mensal para a escala sazonal, representativas das quatro estações do ano: verão (dezembro, janeiro e fevereiro); outono (março, abril e maio); inverno (junho, julho e agosto) e primavera (setembro, outubro e novembro).

Posteriormente, a planilha com os totais sazonais foi importada para o software Idrisi, no qual foi elaborado um produto sazonal para cada ano. Cada um destes mapas foi convertido em formato raster, composto por uma malha fina de células de grade (pixels) que incorpora um valor numérico. De acordo com Ely e Dubreuil (2017), cada pixel das imagens geradas tem uma resolução espacial de $1 \times 1$ quilômetros.

A etapa seguinte se constituiu na submissão dessas imagens a um filtro digital. Os filtros digitais produzem uma operação matemática entre o valor da célula original e de seus vizinhos mais próximos radialmente com o objetivo de extrapolar o valor da célula para uma área maior. Na modelagem realizada foi empregado o filtro $5 \times 5$.

As imagens produzidas com a aplicação do referido filtro foram manipuladas com os recursos da ferramenta Earth Trends Modeler do software Idrisi, conforme metodologia proposta por Ely e Dubreuil (2017), resultando em produtos com as informações derivadas da: Correlação Linear e seu respectivo coeficiente de determinação (R2), tendência linear (OLS), significância de Mann-Kendall (MK Z) e tendência monotônica de Mann-Kendall (MK Tau).

A Correlação Linear (R2) mapeia os valores de cada pixel ao longo do tempo, com a finalidade de identificar tendências positivas, neutras ou negativas (EASTMAN, 2012). Segundo Rogerson (2012), para que os resultados do cálculo de R2 sejam significativos para a série temporal analisada (39 anos) e considerando uma significância de $10 \%$, os valores resultantes desta estatística devem ser superiores a 0.264 (para positivo) ou inferiores a -0.264 (para negativo); logo os índices que estiverem abaixo ou acima desse limiar serão tendências expressivas. A significância de Mann-Kendall (MK Z) trata de um teste não paramétrico que é comumente utilizado como ferramenta para determinação de 
uma mediana, para verificar a existência de uma tendência temporal de alteração estatisticamente significativa, sendo esta aplicação pouco influenciada por mudanças abruptas na série temporal. Já a tendência monotônica de Mann-Kendall (MK Tau) é indicadora de tendência não linear, na qual são medidos o aumento ou regressão de tendências. Para isto é utilizado como referência o intervalo entre -1 e +1 em que os valores próximos de +1 indicam uma tendência de crescimento contínuo e os índices com valores próximos de -1 indicam queda progressiva. Já os valores próximos de 0 (zero) representam um intervalo sem tendências consistentes, permitindo a comparação de índices entre estações com quantidades de chuvas muito diferentes (EASTMAN, 2012). Para que os valores das estatísticas de Mann-Kendall sejam considerados significativos foi utilizado o mesmo limiar calculado para a estatística R2, ou seja, superior a 0.264 ou inferior a -0.246 (ELY; DUBREUIL, 2017).

Ainda, para auxiliar na apresentação da distribuição de frequência dos dados neste estudo, também foram utilizados os gráficos no formato Box Plot que permite analisar: a medida de suas dispersões no entorno da média por meio do desvio padrão, a posição de sua mediana, assimetria, valores máximos e mínimos e a presença de pontos discrepantes ou outliers e extremos (LEM et al., 2013; SCHNEIDER; SILVA, 2014).

No interior do box plot (caixa) são classificados três quartis (Q) com 25\% dos dados cada, além do valor da mediana que equivale ao segundo quartil - $50 \%$ dos dados (LEM et al., 2013; SCHNEIDER; SILVA, 2014). Os outliers são divididos em discrepantes (valores acima do considerado máximo, mas que não são extremos) e extremos, sendo considerados quaisquer valores superiores a Q3 + 1,5 (Q3 - Q1) ou inferiores a Q1 - 1,5 (Q3 - Q1). Os máximos e mínimos são considerados os maiores valores da série, mas que não são extremos ou discrepantes (LEM et al., 2013).

Para a identificação das ocorrências dos alagamentos, enxurradas e inundações na área da bacia foram utilizados os dados disponibilizados pela Defesa Civil do Paraná, por meio de sua coordenadoria regional que produz os relatórios de ocorrência destes eventos. Para a elaboração deste artigo foram coletados os dados referentes aos números de ocorrências, pessoas afetadas e óbitos. Para a análise sazonal das ocorrências de alagamentos, enxurradas e inundações os dados de todos os municípios foram agrupados e contabilizado o total de episódios por estação. 


\section{RESULTADOS}

\section{Variabilidade Pluviométrica}

A precipitação na bacia hidrográfica do rio Ivaí $(P R)$ é distribuída durante todo ano, sem estação seca definida (Figura 2). O verão é a estação mais chuvosa, com pluviometria média que varia de 450 milímetros no extremo norte a 600 milímetros no sudoeste da bacia. Esta distribuição da precipitação evidencia a atuação do relevo que produz maiores volumes na porção mais alta da bacia, enquanto na porção mais baixa do relevo são observados os menores volumes pluviométricos.

Figura 2 - Precipitação média sazonal na Bacia Hidrográfica do Rio Ivaí

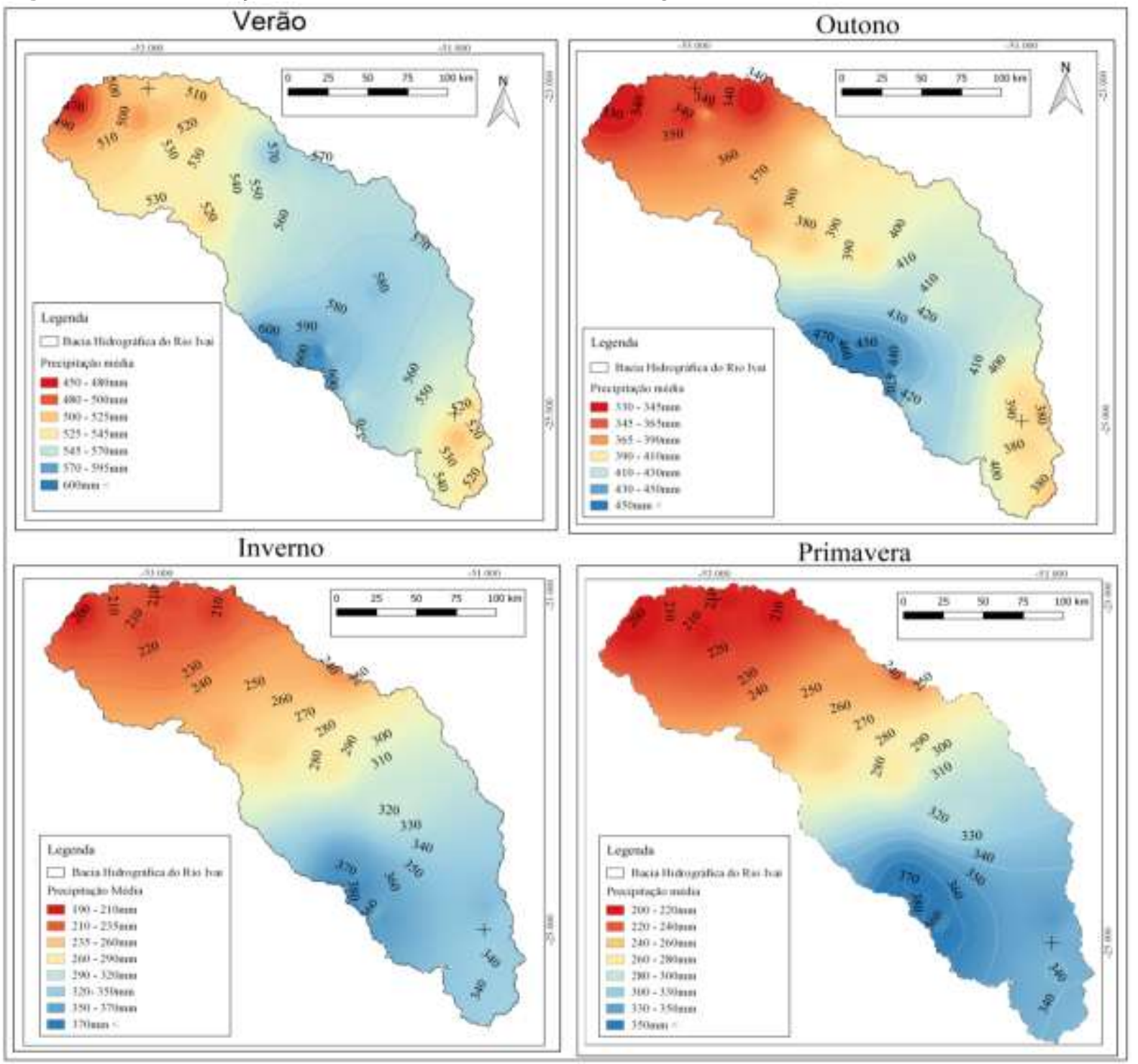

Fonte: organizado pelos autores. 
Para esta mesma área Baldo (2006) identificou um padrão para o regime de chuvas com totais pluviométricos mais elevados à montante nas escalas temporais anual e mensal, devido ao efeito orográfico e à predominância do clima subtropical úmido nesta porção da bacia, enquanto os menores valores de chuva foram observados a jusante, em áreas de baixas altitudes onde prevalece a faixa de transição para o clima tropical.

No outono a precipitação diminui, variando de 330 a 450 milímetros, seguindo a mesma distribuição espacial identificada no verão, com valores maiores na região centro sul e redução no sentido norte e extremo sul, também demonstrando similaridade com o relevo.

No inverno e na primavera a distribuição espacial das chuvas na bacia apresenta um padrão um pouco diferente das outras estações do ano, destacam-se maiores valores na porção sul enquanto os menores estão localizados no norte da bacia, com uma ruptura acentuada em sua porção central. O inverno é a estação menos chuvosa, com precipitação média variando de 190 a 370 milímetros, enquanto na primavera é registrado um leve aumento dos valores médios (200 e 380 milímetros).

As chuvas no outono e inverno são formadas, em sua maioria, por frentes frias, que são caracterizadas pelo encontro da Massa de Ar Polar com a massa de ar quente continental; com o advento da umidade geram uma forte instabilidade atmosférica, podendo levar à formação de cumulunimbus e acarretar a formação de tempestades severas, podendo vir acompanhada de fortes rajadas de vento e de precipitação de granizo ou, ainda, de chuva de intensidade fraca a moderada, mas com duração de dias, se essa vier a ser estacionária (BEREZUK; SANT'ANNA NETO, 2006, 2017; CALDANA et al., 2018; CALDANA et al., 2019; HOLLEMAN, 2001; KUNZ; SANDER; KOTTMEIER, 2009; PUNGE et al., 2017; SANCHEZ et al., 2017). Essas têm atuação, principalmente, no outono, inverno e início da primavera e são responsáveis pelas elevadas alturas pluviométricas na região.

A Massa de Ar Polar tem trajetória favorecida pela calha do Rio Paraná e posteriormente Rio Iguaçu, tendo grande impacto na chuva da região, se deslocando pelo interior do estado (CALDANA et al., 2018; CALDANA et al., 2019). As frentes frias são identificadas em imagens de satélite por uma grande linha de instabilidade que avança no estado do Paraná no sentido Sudoeste-Nordeste (BEREZUK; SANT'ANNA NETO, 2006, 2017; CALDANA et al., 2018; CALDANA et al., 2019; HOLLEMAN, 2001). E como observado, o relevo na porção sul da região possui rápida ascensão, de 200 a 800 metros (Figura 1); esse choque com o relevo pode trazer mais chuva na porção mais alta da região, próximo a Prudentópolis e Guarapuava.

Para complementar a análise da variabilidade pluviométrica sazonal foi elaborado um gráfico box plot (Figura 3) que possibilitou identificar os maiores valores médios da pluviosidade no verão, que foram: 860 milímetros (valor máximo) e 320 milímetros (mínimo); demonstrando uma grande variabilidade para esta época do ano. No inverno os respectivos 
valores foram: 580 milímetros (máximo) e 98 milímetros (mínimos), ou seja, os menores valores pluviométricos médios na bacia; este último foi o menor valor registrado na série analisada. Para a estação do outono observou-se variação na faixa de 640 milímetros a 202 milímetros. No outono foram constatados outliers discrepantes, equivalentes a 859 milímetros e 819 milímetros. A estação de primavera apresentou a maior diferença entre os valores mínimos e máximos do box plot, com aproximadamente 600 milímetros de amplitude, demonstrando grande diferença entre os anos secos e chuvosos neste período do ano.

Figura 3 - Box plot da precipitação média na Bacia Hidrográfica do Rio Ivaí (PR)

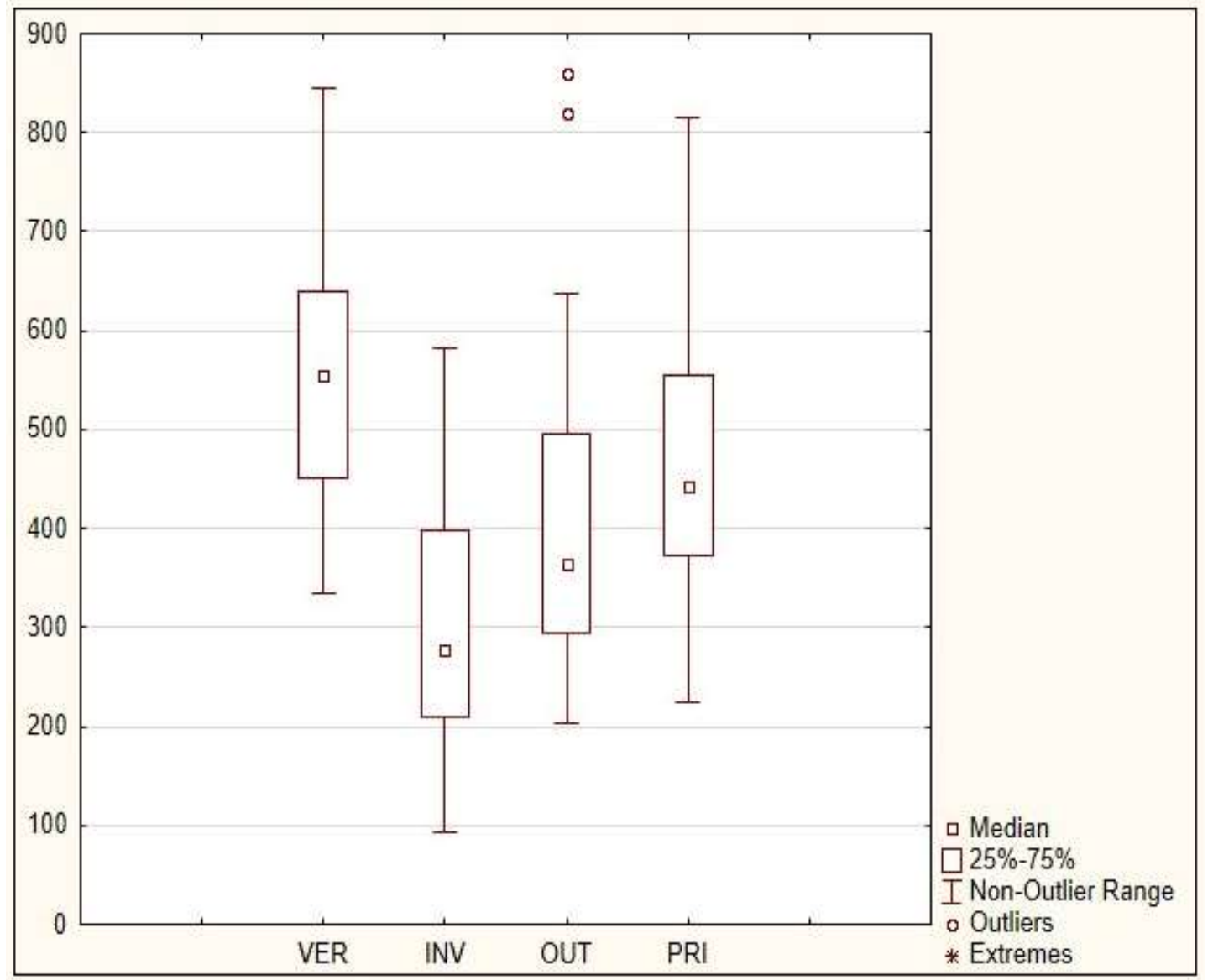

Fonte: organizado pelos autores.

\section{Tendência da Precipitação}

Como destacado anteriormente, o verão é a estação mais chuvosa na bacia. Os testes da correlação linear (Figura 4) demonstram uma tendência à redução das chuvas na porção sul da bacia neste período do ano. Mas vale destacar que, considerando a significância de $10 \%$, estas reduções não são estatisticamente significativas, enquanto que na porção noroeste são verificadas tendências positivas significativas de aumento da pluviosidade, com valores de $R^{2}$ superiores a 0,26. 
Figura 4 - Resultados das aplicações estatísticas para o verão
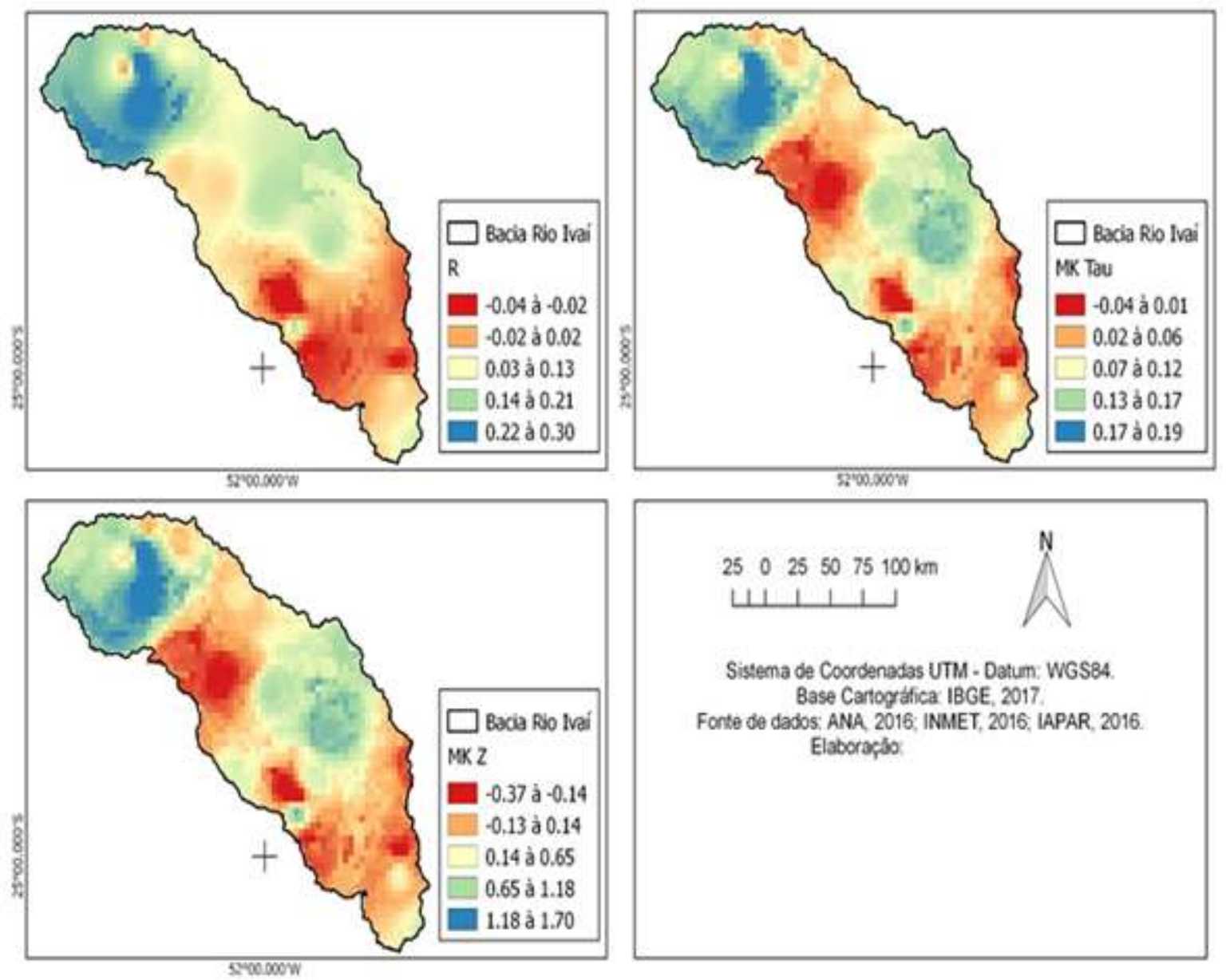

Fonte: organizado pelos autores.

Para o teste significância de Mann-Kendall (Figura 4) observa-se que as porções sul e oeste da bacia apresentam tendência à redução nos totais pluviométricos do verão e aumento nas áreas a noroeste e leste, enquanto a tendência monotônica (Figura 4) apresenta valores de curtos intervalos (mínimo -0,04 e máximo 0,19) ao longo de toda a extensão da bacia. Os resultados das duas estatísticas apresentaram espacializações semelhantes, ou seja, redução da pluviosidade no verão nas porções sul e oeste da bacia e aumento a leste e a noroeste.

Para o outono as estatísticas produziram uma espacialização mais homogênea das tendências (Figura 5). O sul da bacia apresenta redução dos totais pluviométricos, mas a porção noroeste registra aumento. Os resultados da estatística $R^{2}$ demonstram tendência negativa para as porções sul e central da bacia, enquanto no Noroeste, próximo a foz do rio Ivaí, ocorre tendência positiva com valores significativos (superior ao limite t de 0,26 ). Com base nos resultados desta estatística, os valores negativos do outono foram maiores que os registrados para o verão, podendo-se afirmar a ocorrência de redução dos totais pluviométricos nesta época do ano. 
Figura 5 - Resultados das aplicações estatísticas para o outono
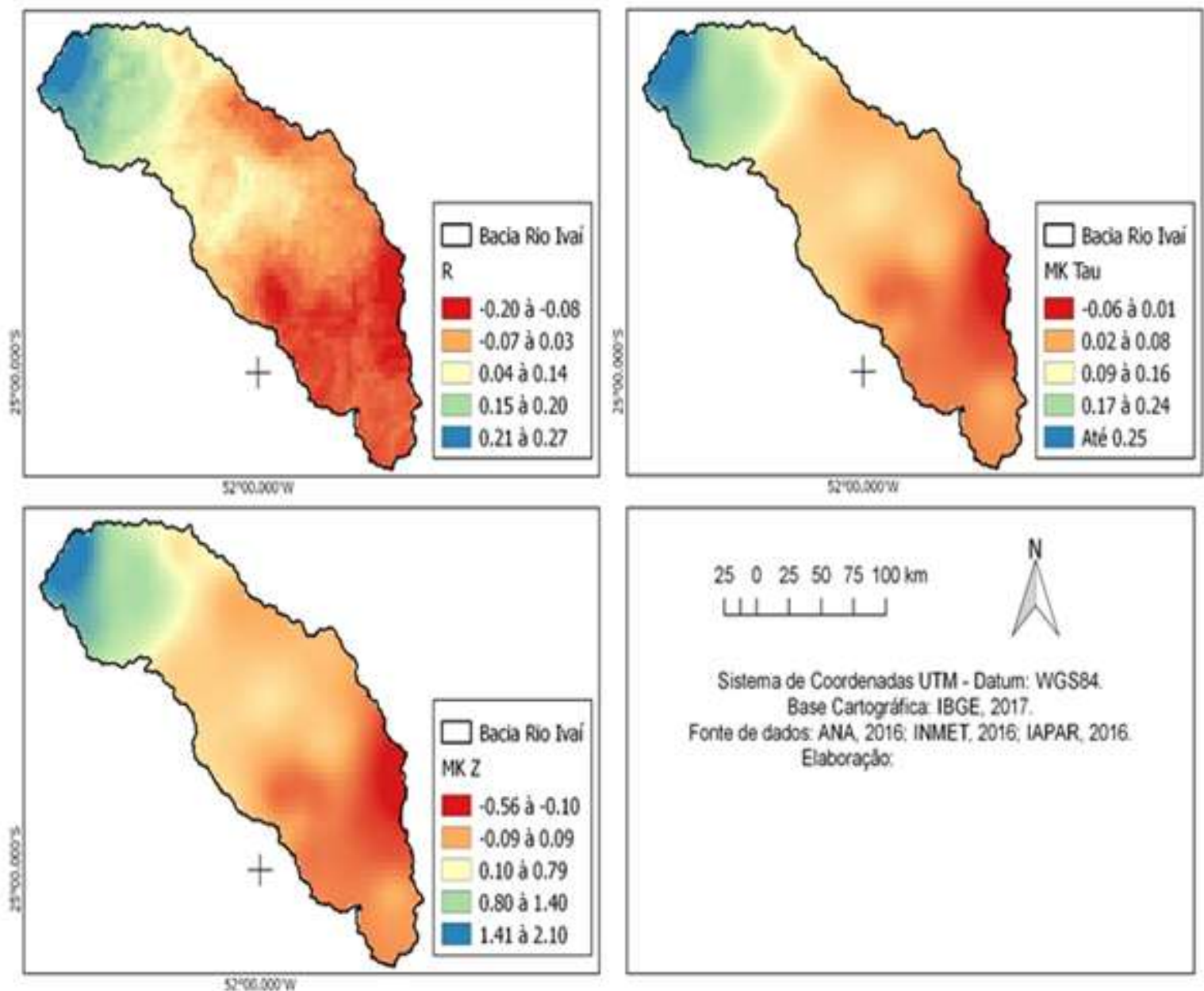

Fonte: organizado pelos autores.

Os resultados produzidos com a estatística MK Z (Figura 5) permitiram identificar um padrão semelhante ao das demais tendências, em que as regiões sul e leste da bacia registram uma redução enquanto em uma pequena parcela a noroeste ocorre aumento.

Por meio da estatística MK Tau (Figura 5) foi possível identificar que o sudeste da bacia apresenta tendência à diminuição das chuvas, mas os valores registrados não são estatisticamente significativos, enquanto no Noroeste as tendências são positivas apresentam valores mais próximos do limiar de significância $(0,25)$.

Para a estação de inverno (Figura 6) as tendências identificadas pelas estatísticas mostram um padrão espacial diferente daqueles do verão e outono, ou seja, não são registradas tendências negativas significativas, com valores bem próximos a zero (0). Apenas uma pequena porção no noroeste da bacia apresentou valores próximos a 0,25. 
Figura 6 - Resultados das aplicações estatísticas para o inverno
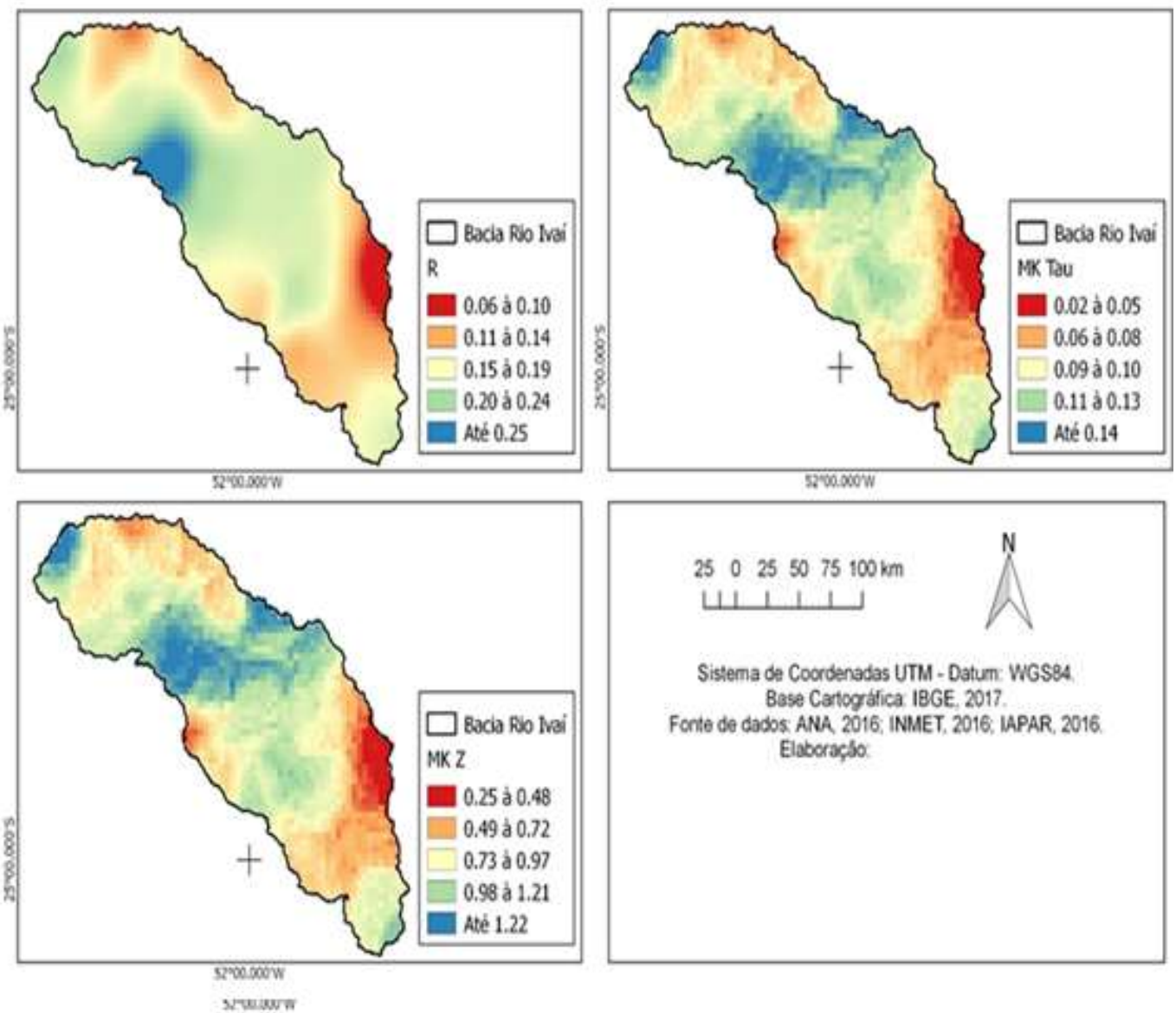

Fonte: organizado pelos autores.

A primavera (Figura 7) apresenta tendências para o aumento das precipitações no sul da bacia, enquanto que no noroeste são registradas reduções. Mas vale salientar que, assim como para o inverno, os valores calculados não atingem o limite de significância ($0,26)$. 
Figura 7 - Resultados das aplicações estatísticas para o inverno
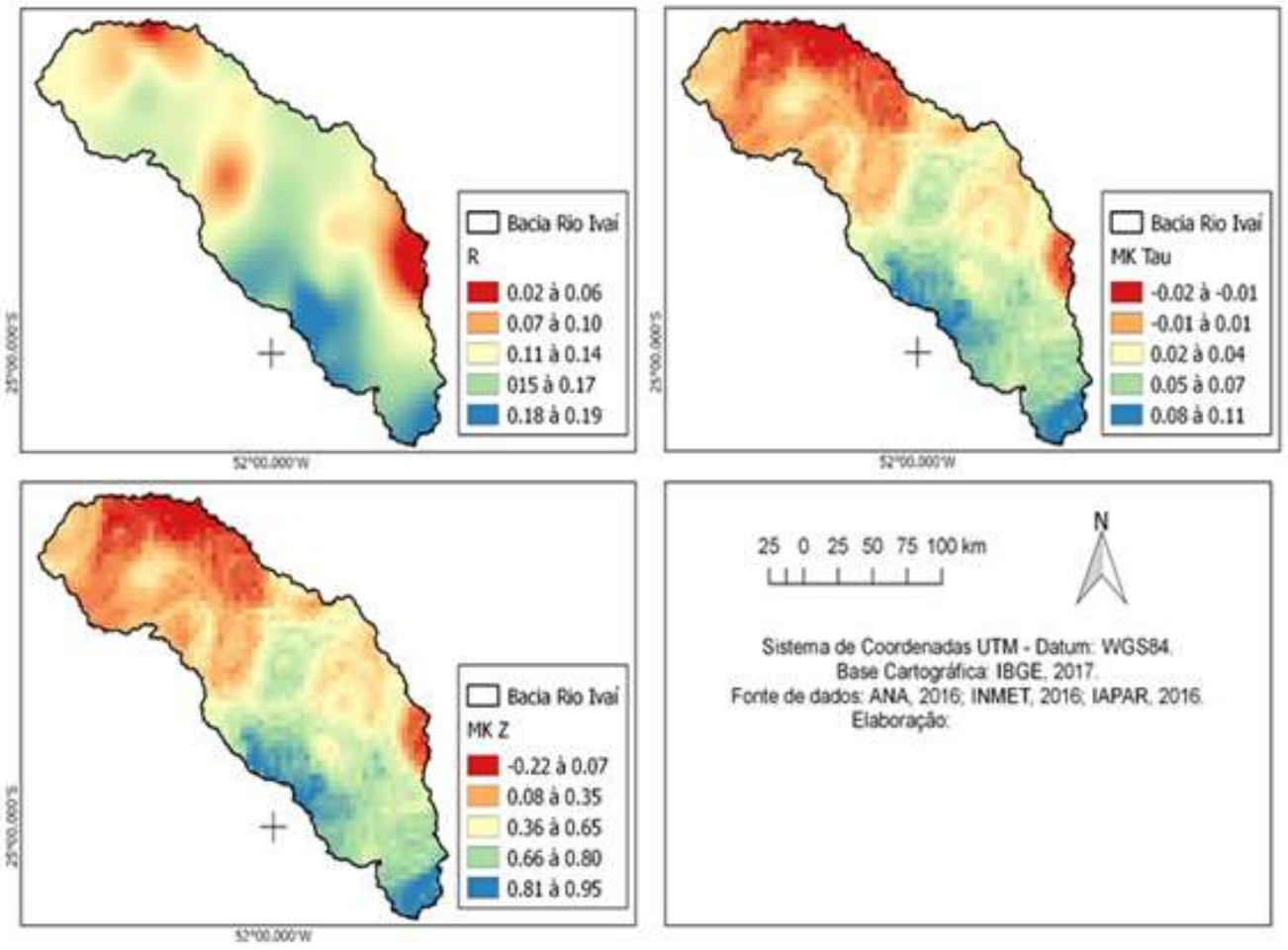

Fonte: organizado pelos autores.

\section{Eventos extremos relacionados à precipitação}

Para identificar os impactos da chuva na bacia, foram utilizados dados de ocorrência de alagamentos, enxurradas ou enchentes nos municípios com área na bacia (Figura 8). Cabe destacar que a ocorrências destes eventos são respostas aos eventos extremos de precipitação, ou seja, precipitação com alturas elevadas em intervalo de tempo considerado curto (MARCELINO, 2007).

Grande parte das cidades do norte do Paraná teve uma urbanização rápida e acentuada no século XX (FRESCA, 2004), que pode ter ocasionado problemas no planejamento urbano produzindo uma vulnerabilidade socioambiental em alguns municípios da região. Neste cenário, Mendonça (2004, p. 148) destaca "[...] que os grandes riscos e vulnerabilidades socioambientais estão diretamente relacionados ao número e concentração da população e à pobreza urbana, sobretudo nas periferias das cidades".

Por meio da figura 8 foi identificado que a maioria dos municípios inseridos na bacia do rio Ivaí registrou ao menos uma ocorrência de um dos desastres hidroclimatológicos estudados no período de 1990 a 2015. Os municípios localizados nos extremos norte e sul da bacia foram os que registraram maior número de ocorrências. Vale ressaltar que, de acordo com as tendências pluviométricas sazonais positivas identificadas nestas áreas, esses resultados podem se tornar mais alarmantes. 
Figura 8 - Ocorrências de alagamento, enxurradas ou inundações na Bacia Hidrográfica do Rio Ivaí

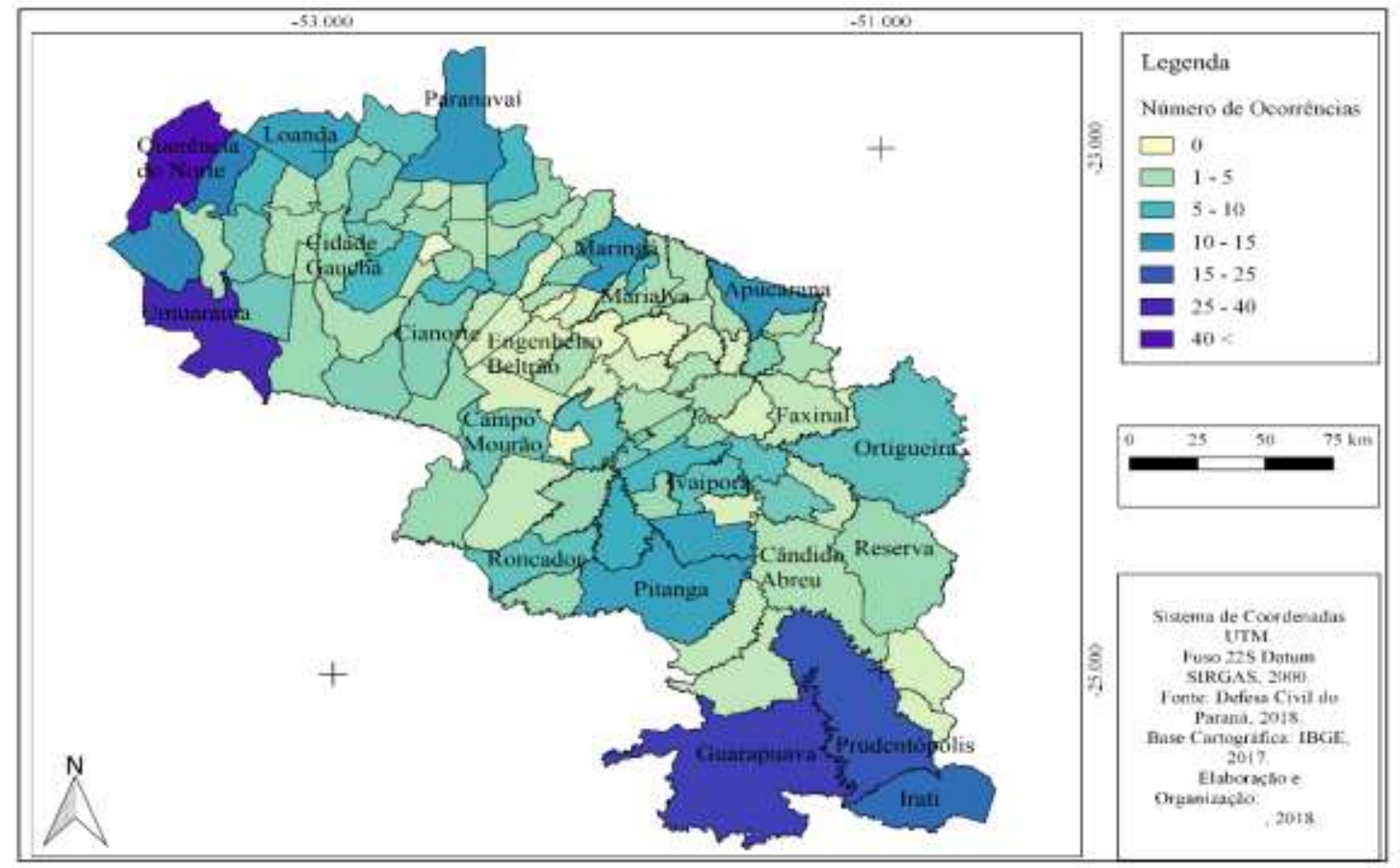

Fonte: organizado pelos autores.

Os municípios de Querência do Norte e Umuarama registraram mais de 40 ocorrências no período analisado. Os municípios do extremo sul da bacia (Guarapuava, Irati e Prudentópolis), também registraram um elevado número de ocorrências destes desastres, enquanto que os municípios da porção central obtiveram menores registros, mesmo sendo a região que concentra maior volume pluviométrico, mas com menores altitudes, demostrando uma influência importante da topografia nas ocorrências de alagamentos, enxurradas e inundações, além da geometria urbana e ocorrência de locais de concentração da população.

Para complementar a análise das ocorrências de alagamentos, enxurradas e inundações na bacia, também foi utilizada a frequência que os municípios decretaram situação de emergência ou calamidade pública (Figura 9).

Ao longo da série temporal foram decretadas 127 situações de emergência ou calamidade pública nos municípios localizados na bacia. Santa Cruz do Monte Castelo foi o município que decretou situação de emergência com maior frequência (dez ao total, sendo cinco de emergência e cinco de calamidade pública). Querência do Norte e Loanda se destacaram com seis decretos ao todo, estes municípios estão localizados na porção da bacia que apresentou significância para o aumento da precipitação, enquanto no sul da bacia destacam-se os municípios de Guarapuava, Prudentópolis, Irati e Pitanga pelo número 
de ocorrências. Mais uma vez, a porção central da bacia foi a que menos registrou decretos de situação de emergência ou de calamidade pública.

Figura 9 - Ocorrências de situação de emergência ou calamidade pública por alagamento, enxurradas ou inundações na Bacia Hidrográfica do Rio Ivaí

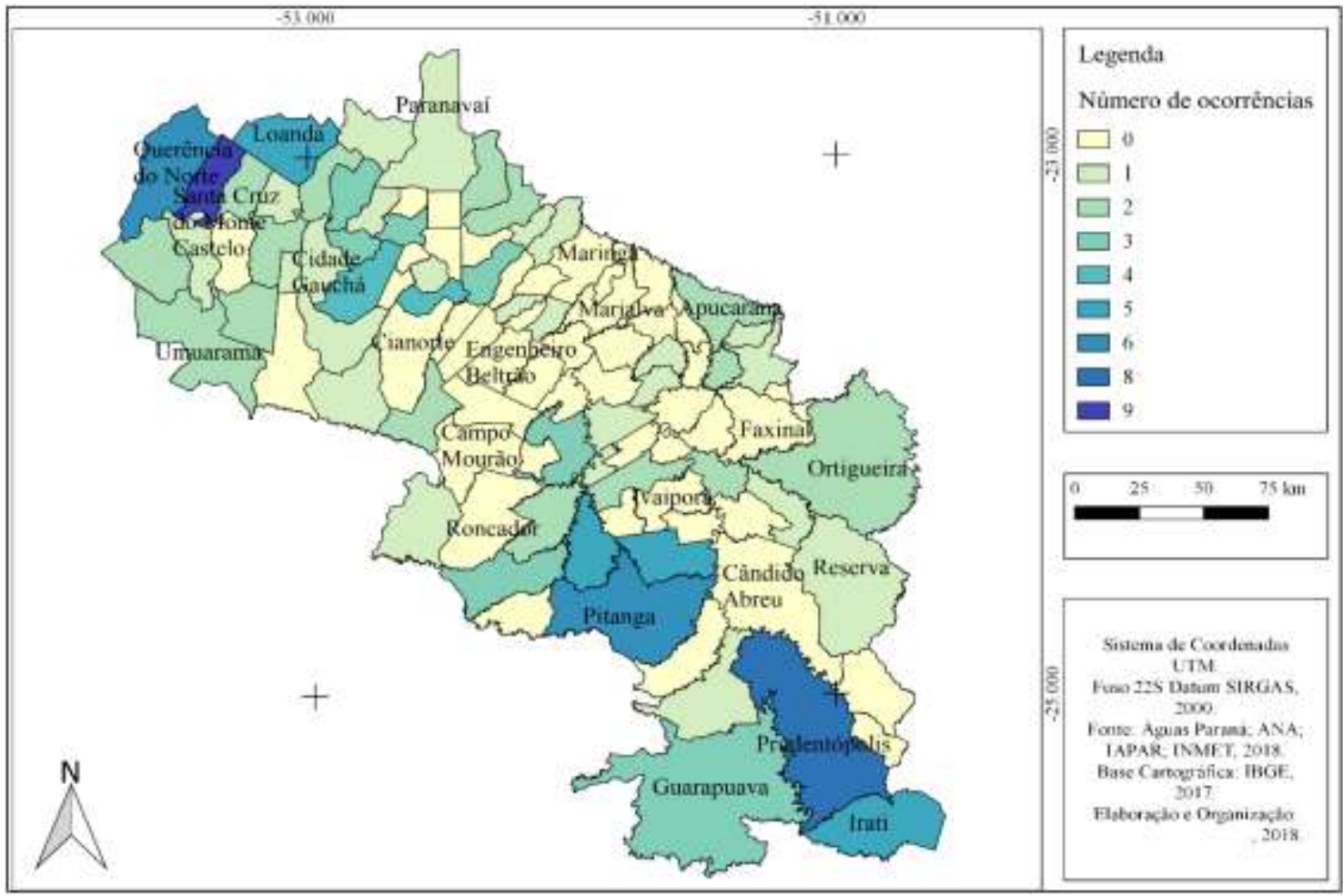

Fonte: organizado pelos autores.

Quanto ao número de pessoas afetadas por um dos três desastres (Figura 10), destacam-se os municípios de Apucarana e Maringá por serem municípios com um maior contingente populacional (IBGE, 2018). Mesmo com menores ocorrências de desastres, as ocorrências em tais municípios afetam um maior número de pessoas. Apucarana teve 109 mil e Maringá 75 mil pessoas afetadas por algum tipo de dano relacionado aos desastres ora estudados.

Mesmo com população inferior aos dois municípios citados anteriormente, Prudentópolis registrou mais de 100 mil pessoas afetadas em todo o período, sendo que o município conta atualmente com 49 mil habitantes (IBGE, 2018). Esses dados demonstram que tais eventos podem ter afetado as mesmas pessoas mais de uma vez no intervalo de 25 anos de análise e caracterizando sua vulnerabilidade.

Outros municípios com população inferior a 50 mil que, também, se destacaram pelo número de pessoas afetadas foram: Pitanga (66.359), Irati (45.722) e Querência do Norte (28.817) (Figura 9). Novamente os municípios localizados na região central da bacia não registraram a ocorrência de nenhum impacto relacionado aos desastres analisados. Com 
objetivo de articular os dados obtidos com as tendências pluviométricas sazonais e com as ocorrências dos desastres foi produzido o gráfico da figura 11.

Figura 10 - Pessoas afetadas em ocorrências de alagamento, enxurradas ou inundações na Bacia Hidrográfica do Rio Ivaí

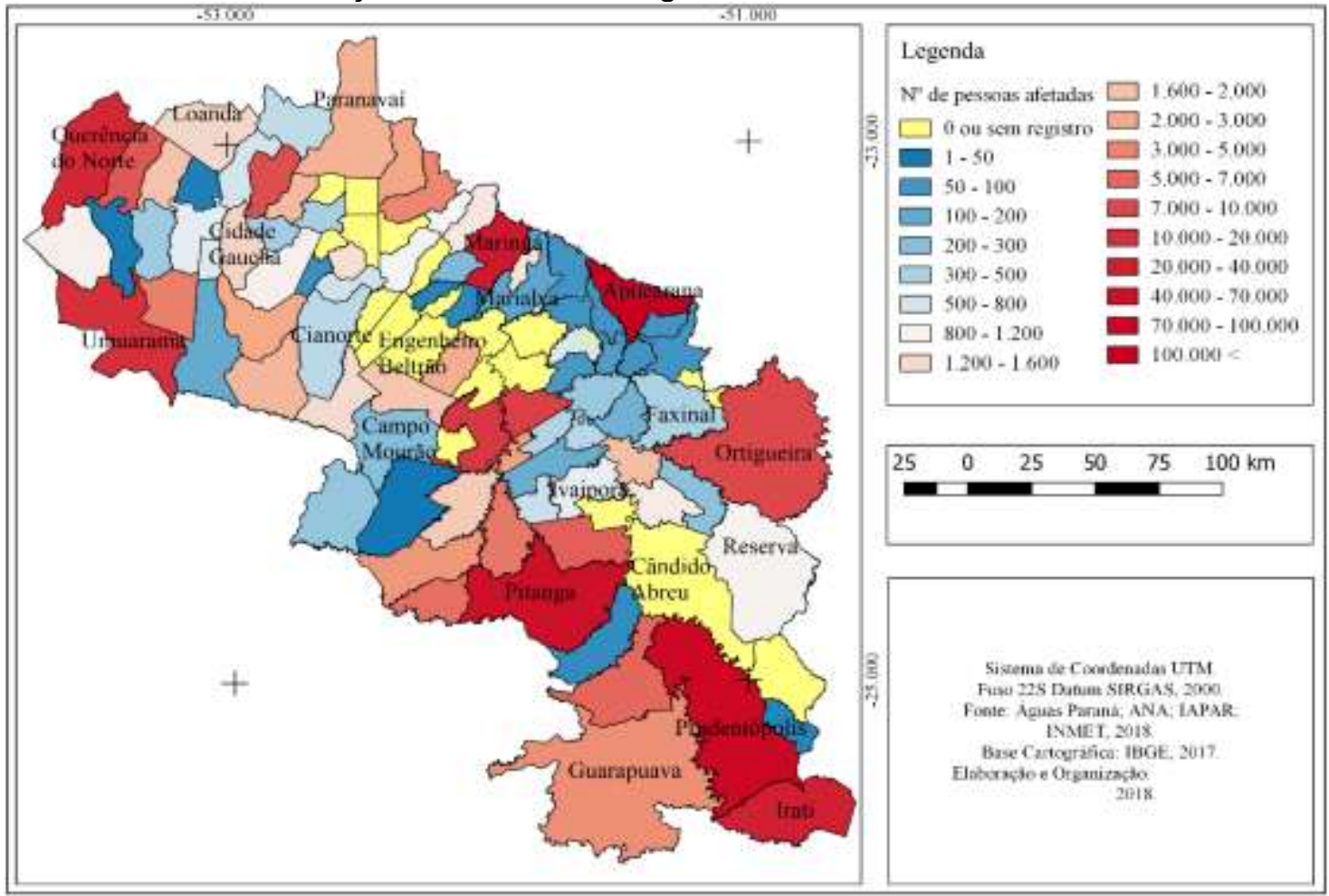

Fonte: organizado pelos autores.

No gráfico da figura 11 visualiza-se que a estação da primavera concentra 47 decretos de situação de emergência ou calamidade pública vinculados a alagamentos, enxurradas ou inundações na bacia do rio Ivaí. Mesmo não sendo a estação mais chuvosa, foi nesta época do ano que foi identificada tendência ao aumento da precipitação na bacia. $E$, justamente, na porção sul da bacia, onde estão localizados os municípios de Prudentópolis, Irati, Guarapuava e Pitanga.

Ainda de acordo com os dados do gráfico da figura 11, na sequência, a estação do verão conta com 42 decretos, período mais chuvoso na bacia e com tendência de aumento das chuvas em suas porções sul e central. No outono e no inverno, também, foram observadas tendência de aumento das precipitações, mas com valores estatisticamente não significativos, nas porções centro e sul onde os registros de decretos foram 26 e 12 , respectivamente.

Problemas socioambientais decorrentes de alagamentos, inundações e enxurradas são frequentes em todo o mundo e, como mencionado anteriormente, estão presentes em aproximadamente $80 \%$ das cidades brasileiras. Nas últimas décadas estes eventos ganharam maior atenção pública e investimentos em infraestrutura, concentrados 
principalmente nas grandes cidades (CHEN et al., 2018; MARCELINO, 2007). Na bacia do rio Ivaí constata-se que tais problemas estão presentes em pelo menos $90 \%$ de seus municípios. Portanto, o planejamento dessa região sempre deve ser realizado com medidas que visem à melhoria da drenagem urbana, mitigando assim, esse tipo de ocorrência e, consequentemente, melhorando a qualidade ambiental e hídrica da bacia.

Figura 11 - Decretos de situação de emergência ou calamidade pública por estação do ano na Bacia Hidrográfica do Rio Ivaí (1990 - 2015)

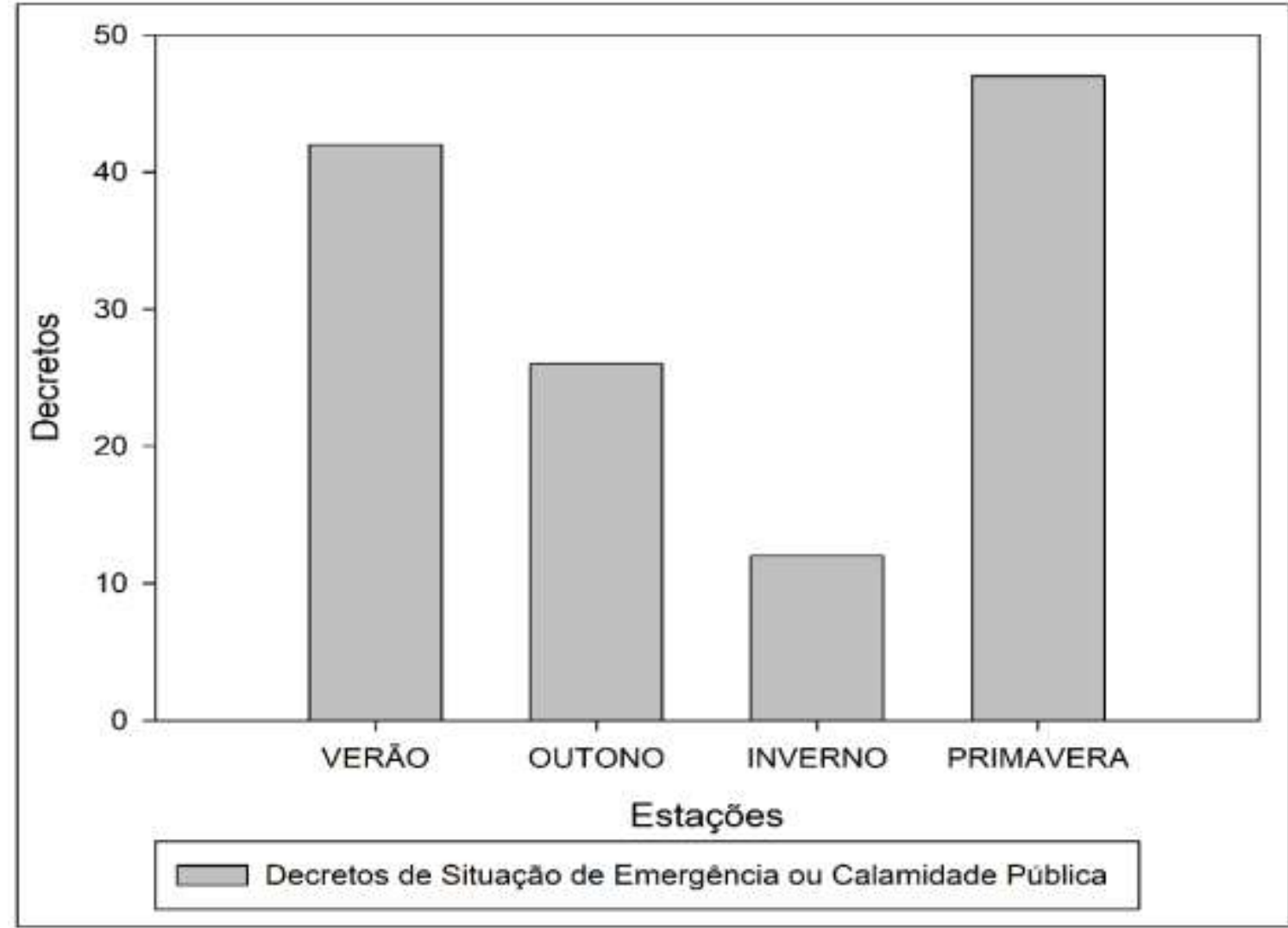

Fonte: organizado pelos autores.

\section{CONSIDERAÇÕES FINAIS}

Com o desenvolvimento do presente artigo foi possível identificar que o verão e o outono são as estações que apresentaram tendências mais acentuadas à redução da precipitação, mas concentradas no sul e leste da bacia, enquanto nas regiões centrais, norte e noroeste predominam tendências de aumento da pluviosidade. Cabe destacar que o verão é a estação mais chuvosa. No outono, por registrar menores alturas pluviométricas, as tendências negativas podem ser mais abrangentes.

O inverno é a estação em que não são registradas tendências significativas, e a primavera apresentou tendências pluviométricas positivas. As três estatísticas apontaram uma tendência de redução pluviométrica para as regiões norte e noroeste da bacia, 
enquanto que para as demais estações do ano essas áreas haviam sido classificadas com uma tendência positiva. O mesmo, também, ocorreu para a porção sul da bacia que, para as demais estações, foi classificada com tendência à redução e, no entanto, para a primavera obteve tendência ao aumento dos totais pluviométricos.

A porção central da bacia se destaca pela menor vulnerabilidade aos desastres naturais relacionados às enxurradas, alagamentos e enchentes, mesmo sendo a área com maiores totais pluviométricos, enquanto os extremos norte e sul não registraram maior número de ocorrências dos referidos desastres. Estas porções da bacia não concentram as maiores alturas pluviométricas, mas registraram tendências positivas nas precipitações sazonais e onde as altitudes são mais baixas; demonstrado a necessidade de mapeamentos mais detalhados dos vales dos afluentes e do curso principal do rio Ivaí para melhor contribuir com o planejamento e a mitigação dos impactos analisados.

\section{REFERÊNCIAS}

AGOVINO, M.; CASACCIA, M.; CIOMMI, M.; FERRARA, M.; MARCHESANO, K. Agriculture, climate change and sustainability: the case of EU-28. Ecological Indicators, Coimbra, v. 105, p. 525-543, 2019.

AYOADE, J. O. Introdução à climatologia para os trópicos. Tradução de Maria Juraci Zani dos Santos. São Paulo: Difel, 1986.

BALDO, M. C. Variabilidade pluviométrica e a dinâmica atmosférica na bacia

hidrográfica do rio Ivaí-PR. 2006. Tese (Doutorado em Geografia) - Universidade Estadual Paulista, Presidente Prudente, 2006.

BEREZUK, A. G.; SANT'ANNA NETO, J. M. Eventos climáticos extremos no oeste paulista e norte do Paraná, nos anos de 1997, 1998 e 2001. Revista Brasileira de Climatologia, Curitiba, v. 2, p. 9-22, 2006.

BEREZUK, A. G.; SANT'ANNA NETO, J. M. Eventos extremos: estudo da chuva de granizo de 21 de abril de 2008 na cidade de Maringá-PR. Revista Brasileira de Climatologia, Curitiba, v. 5, p. 153-164, 2017.

BERLATO, M. A.; FONTANA, D. C. EI Niño e La Niña: impactos no clima, na vegetação e na agricultura do Rio Grande do Sul; aplicações de previsões climáticas na agricultura. Porto Alegre: UFRGS, 2003.

CALDANA, N. F. S.; MARTELÓCIO, A. C. Gênese, frequência e intensidade das precipitações de granizo nas mesorregiões centro oriental e sudeste paranaense, Brasil. Geotextos, Salvador, v. 15, p. 205-229, 2019.

CALDANA, N. F. S.; RUDKE, A. P.; SILVA, I.; NITSCHE, P. R.; CARAMORI, P. H. Gênese, impacto e a variabilidade das precipitações de granizo na mesorregião centro-sul paranaense, Brasil. Caderno de Geografia, Belo Horizonte, v. 29, p. 61-80, 2019.

CALDANA, N. F. S.; YADA JUNIOR, G. M.; MOURA, D. A. V.; COSTA, A. B. F.; CARAMORI, P. H. Ocorrências de alagamentos, enxurradas e inundações e a variabilidade pluviométrica na bacia hidrográfica do rio Iguaçu. Revista Brasileira de Climatologia, Curitiba, v. 23, p. 343-355, 2018. 
CHEN, W.; HUANG, G.; ZHANG, H.; WANG, W. Urban inundation response to rainstorm patterns with a coupled hydrodynamic model: A case study in Haidian Island, China. Journal of Hydrology, United States, v. 564, p. 1022-1035, 2018.

CONTI, J. B. Considerações sobre as mudanças climáticas globais. Revista do Departamento de Geografia, São Paulo, v. 16, p. 70-75, 2005.

EASTMAN, J. R. IDRISI Selva manual, version 17.01. Worcester, MA: Clark Labs, 2012.

ELY, D. F.; DUBREUIL, V. Análise das tendências espaço-temporais das precipitações anuais para o estado do Paraná - Brasil. Revista Brasileira de Climatologia, Curitiba, v. 21, p. 553-569, 2017.

FRESCA, T. M. Industrialização no Norte do Paraná na década de 1990: transferência industrial e estratégias de crescimento. Ciência Geográfica, Bauru, v. 10, p. 195-206, 2004.

HAMMOND, M. J.; CHEN, A. S.; DJORDJEVIC, S.; BUTLER, D.; MARL, O. Urban flood impact assessment: a state-of-the-art review. Urban Water Journal, London, v. 12, n. 1, p. 14-29, 2015.

HOLLEMAN, I. Hail detection using single-polarization radar. Ministerie van Verkeer en Waterstaat, Koninklijk. Nederlands: Meteorologisch Instituut, 2001.

HUANG, K.; CHEN, L.; ZHOU, J.; ZHANG, J.; SINGH, V. P. Flood hydrograph coincidence analysis for mainstream and its tributaries. Journal of Hydrology, Amsterdam, v. 65, p. 341353, 2018.

IBGE. Censo demográfico: Brasil, 2017. Rio de Janeiro: IBGE, 2018.

IPCC. Technical summary. In: IPCC. Climate change 2013: the physical science basis. Contribution of working group to the fifth assessment report of the intergovernmental panel on climate change. Cambridge: Cambridge University Press, 2013. p. 33-115.

JAMALI, B.; LÖWE, R.; BACH, P. M.; URICH, C. A rapid urban flood inundation and damage assessment model. Journal of Hydrology, Amsterdam, v. 564, p. 1085-1098, 2018.

KARIMI, V.; KARAMI, E.; KESHAVARZ, M. Climate change and agriculture: Impacts and adaptive responses in Iran. Journal of Integrative Agriculture, Beijing, v. 17, n. 1, p. 1-15, 2018.

KARIMI, V.; KARAMI, E.; KESHAVARZ, M. Vulnerability and Adaptation of livestock producers to climate variability and change. Rangeland Ecology \& Management, Lakewood, v. 71, n. 2, p. 175-184, 2017.

KUNZ, M.; SANDER, J.; KOTTMEIER, C. Recent trends of thunderstorm and hailstorm frequency and their relation to atmospheric characteristics in southwest Germany.

International Journal of Climatology: a journal of the royal meteorological society, New York, v. 29, n. 15, p. 2283-2297, 2009.

LEE, J. T.; KO, K. Y.; LEE, D. I.; YOU, C. H.; LIOU, Y. C. Enhancement of orographic precipitation in Jeju Island during the passage of Typhoon Khanun (2012). Atmospheric Research, Amsterdam, v. 201, p. 58-71, 2018.

LEM, S.; ONGHENA, P.; VERSCHAFFEL, L.; VAN DOOREN, W. The heuristic interpretation of box plots. Learning and Instruction, Oxford, v. 26, p. 22-35, 2013.

LUNGARSKA, A.; CHAKIR, R. Climate induced land use change in France: impacts of agricultural adaptation and climate change mitigation. Ecological Economics, Amsterdam, v. 147, p. 134-154, 2018.

MARCELINO, E. V. Desastres naturais e geotecnologias: conceitos básicos. Santa Maria: INPE, 2007. 
MENDONÇA, F. Riscos, vulnerabilidade e abordagem socioambiental urbana: uma reflexão a partir da RMC e de Curitiba. Desenvolvimento e Meio Ambiente, Curitiba, n. 10, p. 139148, jul./dez. 2004.

MUELLER, T. G.; PUSULURI, N. B.; MATHIAS, K. K.; CORNELIUS, P. L.; BARNHISEL, R. I.; SHEARER, S. A. Map quality for ordinary kriging and inverse distance weighted interpolation. Soil Science Society of America Journal, Madison, WI, v. 68, n. 6, p. 20422047, 2004.

PAILLER, S.; TSANEVA, M. The effects of climate variability on psychological well-being in India. World Development, London, v. 106, p. 15-26, 2018.

PARANÁ. Bacias hidrográficas: série histórica. Curitiba: Secretaria do Meio Ambiente, 2013. Disponível em:

http://www.meioambiente.pr.gov.br/arquivos/File/corh/Revista_Bacias_Hidrograficas_2015.p df. Acesso em: 16 dez. 2019.

PATHMESWARAN, C.; LOKUPITIYA, E.; WAIDYARATHNE, K. P.; LOKUPITIYA, R. S. Impact of extreme weather events on coconut productivity in three climatic zones of Sri Lanka. European Journal of Agronomy, Amsterdam, v. 96, p. 47-53, 2018.

PUNGE, H. J.; BEDKA, K. M.; KUNZ, M.; REINBOLD, A. Hail frequency estimation across Europe based on a combination of overshooting top detections and the ERA-INTERIM reanalysis. Atmospheric Research, Amsterdam, v. 198, p. 34-43, 2017.

ROCHA, P. C.; SANT'ANNA NETO, J. L. Ritmo climático e dinâmica limnológica na planície fluvial do alto rio Paraná, centro-sul do Brasil. Revista Brasileira de Climatologia, Curitiba, v. 6, p. 169-188, 2010.

ROGERSON, P. A. Métodos estatísticos para geografia: um guia para o estudante. Porto Alegre: Bookman, 2012.

SANCHES, F. O.; VERDUM, R.; FISCH, G. Tendência de longo prazo das chuvas diárias no Sudoeste do Rio Grande do Sul: os eventos extremos e a arenização. Revista Brasileira de Geografia Física, Recife, v. 7, p. 1100-1109, 2014.

SANCHEZ, J. L.; MERINO, A.; MELCÓN, P.; GARCÍA-ORTEGA, E.; FERNÁNDEZGONZÁLEZ, S.; BERTHET, C.; DESSENS, J. Are meteorological conditions favoring hail precipitation change in Southern Europe? Analysis of the period 1948-2015. Atmospheric Research, Amsterdam, v. 198, p. 1-10, 2017.

SCHNEIDER, H.; SILVA, C. A. O uso do modelo box plot na identificação de anos-padrão secos, chuvosos e habituais na microrregião de Dourados, Mato Grosso do Sul. Revista do Departamento de Geografia, São Paulo, v. 27, p. 131-146, 2014.

SOMBOONSUKE, B.; PHITTHAYAPHINANT, P.; SDOODEE, S.; KONGMANEE, C.

Farmers' perceptions of impacts of climate variability on agriculture and adaptation strategies in Songkhla. Kasetsart Journal of Social Sciences, Bangkok, v. 39, n. 2, p. 277-283, 2018.

TANAKA, T.; TACHIKAWA, Y.; ICHIKAWA, Y.; YOROZU, K. Impact assessment of upstream flooding on extreme flood frequency analysis by incorporating a flood-inundation model for flood risk assessment. Journal of Hydrology, Amsterdam, v. 554, p. 370-382, 2017.

WIRÉHN, L. Nordic agriculture under climate change: A systematic review of challenges, opportunities and adaptation strategies for crop production. Land Use Policy, London, v. 77, p. 63-74, 2018.

Recebido: setembro de 2019. Aceito: janeiro de 2020. 